\title{
Cost Overrun in Construction Projects in Oman: Case Study
}

\author{
Haitham N. S. AL Siyabi ${ }^{1}$ and Omar R. Khaleel"\# \\ ${ }^{1}$ Middle East College, Muscat, Sultanate of Oman \\ \#Advisor
}

ABSTRACT

There are many challenges in construction industry sector, and one of the most important and critical is completion of the project within the original contract value. As the issue of cost overrun in construction projects is spread worldwide generally and commonly encountered in the Sultanate of Oman.The main objectives of this study are to identify and determine vital factors leading to cost overrun in Building Projects in Oman, evaluate the impact of cost overrun in building construction projects and develop the best protocol strategy for project management teams that can be adopted in order to control the cost overrun in future projects. These objectives have been obtained through several methods, questionnaire survey,interviews with experts in construction industry. Twenty nine major factors lead to cost overrun were identified through literature review and studied in Sultanate of Oman.The study concluded that there are three major impacts of cost overrun in construction projects and industry which are time of completion, delivery of poor quality projects and delay of payment approval. Additional to that, Hire good Supervision Team, a good Cost Controller, Project Manager, a good project design team, well planning for pre-contract stage and proper procurement strategy. Consider the Risk assessment and Risk Control are crucial to minimize the cost overrun in building construction project in Oman. The study have recommended procedure to cost control in future project such as the Employer should have a proper tender analysis of the Contractor's bid, Detailed design should be finalized before award of work and others.

\section{Introduction}

Construction industry is considered one of the vital sector generate the economy in every country. (Raykar and A.N. 2016).In Oman the construction industry is contributing $9 \%$ of GDP and country's largest employer (Moossen 2019). Cost performance in construction project is considered one of the major criteria for measuring building construction project success (Abusafiya and Suliman 2017), hence the essential target of any construction project is to facilitate and keep the building functional, within allocated contract budget. Even though the clients are emphasis the significant of that, construction projects have still struggled from the same. In the globe generally and our Sultanate specifically too many projects have been got cost overrun.

According to (Aljohani 2017) the cost escalated is considered as critical obstacle in construction management. To understand the reason behind the cost overrun, it is significant to investigate the source of the issue. Cost overruns happened because of there are many construction project have been done for infrastructure improvement in Oman. The causes of cost overruns are vary from project to other and place to place too, because of variance of different circumstances in that nation (Ramabhadran 2018).

A large percentage of construction project have faced extensive cost overruns which led to lots of complication in projects itself and financial impact and lots of disputes between project managements and stakeholders, even though the government pump lots of investment in construction industry, there are too many cases 
reported about the cost overrun in construction project (4) (Allahaim and Liu 2015). Hence there is an essential requirement for update- to date - about factors behind the cost overrun in construction project in Oman.

This project concentrate to identify and determine vital factors leading to cost overrun in Building Projects in Oman and to evaluate the cost overrun impact of project and to develop the best protocol strategy for project management teams that can be adapted in order to control the cost overrun.

\section{This research has three major objectives:}

To identify and determine vital factors leading to cost overrun in Building Projects in Oman.

To evaluate the impact of project cost overrun in building construction project.

To develop the best protocol strategy for project management teams that can be adopted in order to control the cost overrun.

\section{Methods}

The research methodology is the mechanism use to investigate the roots of problem in scientific and systemic method, in order to reach the causes, according develop appropriate solutions. The approach survey in this research provides mechanism for obtaining information and data that would survey and analyse the data collected then present them as result that would help in the development and identification of recommendations that will reduce the issue. This chapter has following sections.

There are two types of research, either descriptive or investigative. The investigation one is used to verify or investigate an awareness for any particular situations or circumstances. In this study, for the factors lead to cost overrun in construction project in Sultanate of Oman, the descriptive research methodology is the one that will be used. The responses of experts and technical people working in the construction industry sector, would help in assessing the major factors, and obstacles that affected the cost overrun and overall project progress. Finally, determine the measures and mechanism that can limit the problems of cost overrun of construction buildings projects in Oman.

This research has two main mechanisms: the qualitative and quantitative mechanism (Ullah et al. 2016). With regards to the quantitative method, the questionnaire survey would be use in order to obtain the objectives of this research (Shah 2016). For the qualitative mechanism, the interview with experts in construction industry would be approached. This method leads to direct answers, which may guide to ideas and protocols can used to solve the problems or lead to minimize it.

For the research, there are set of required procedures have to conduct in order to get research in a systematic way. As (S. Mulla and P. Waghmare 2015) the research method is considered a pivotal way to abstain data from correct way to make an integrated study from all aspects required for the project.in this study, the quantitative and qualitative method would be approached as following steps.

Identify issues and challenges.

Reviewing relevant data and studies (literature reviews).

Collecting relevant data.

Analysing data in a professional manner.

Interpreting the resulting data obtained from the analysis.

Come up with recommendations and publish them. 
In this project methodology including studding the factors lead of cost overrun in construction project in Oman, what are the impact of cost overrun in construction project and obtained the best protocol and mechanising to mines this issue in coming future. The objectives of this project would be reached as follows methods:

Reviewing the recent sources of literature review.

Distribution questionnaire to different categories in construction industry.

Interviewing experts in Oman building construction industry.

There are two types of data that can be obtained and use in research and studies: the primary and secondary data. The secondary data can be obtained through studies, research and experiments carried out by researchers, the result were obtained use to quantify the assumption developed. The other type is primary data, it can be obtained from various sources as the questioner, interview with experts in construction industry. These information can be obtained faster and easier in current time by using the available communication sources. Additional to that very effective to assess the issue and obtain result close to reality. In this project the questionnaire survey and interview with provisional in construction industry would conduct to obtain the objectives.

In this study, the experts and specialists in construction industry had been chosen to evaluate and assess the major factors leading to cost overrun in construction project in Oman. The sample had been got from various construction categories Client, Contractor, consultant and other related concern in same industry. An extensive number of the responders in all Sultanate area had been targeted. The questionnaires are distributed by online method, because no one can receive visitors in construction site or offices because of pandemic situation of COVID 19.

Generally no agreement among researchers to determine the issues behind the cost overrun in building construction projects. Each study has independent viewpoints, in this regards. Some of them conclude a size of project, others are type of project, location of project, some of them went to the surrounding circumstances of the projects, the contractual aspects and etc.

Hence, this part will be concerned with taking previous studies in all literature reviews aspects and their suitability with the conditions of construction project in Sultanate of Oman.

Since there are numerous number of government organization approaches the building construction projects in Muscat governorate, additional to that several number of consultancy offices and contractors firms deal with privet construction client, a survey consider highly appropriating in this research, questionnaire survey would use the qualitative information what have been got from literature review and using the quantitative measurement to measure the scale from responders, in order to evaluate the results outcome in analysis part (Jangale et al. 2017).The study survey include selected type of questions, which can be analyzed easily because it has provide fix options scale. A pilot survey has been taken in place for experts in order to check the sufficiency of questions before start to distributing the final copy of questionnaire. The intensive evaluated by invited five experts in construction projects field have been done to get their critically feedback and comments for the type of questions and design of questionnaire. Their comments were taken in highly consideration, afterward distributed between the different categories in construction people as selected sample.

Format design and sections of Questionnaire survey

The questionnaire survey included four parts as follows:

\section{Part 1: General Information}

The section one of questionnaire survey is included general information and background of the respondents .It consist six questions as follows: Education Level, organization type, Job designation, Industry type, the value of recently achieved project and finally Percentage extent of cost overrun in projects of the respondent as appendix (A). 


\section{Part 2: Factors leading to Cost Overrun in Building projects in Oman.}

In this part of questionnaire survey is consisted four sub sections, the first sub section is included a list of factors which are led to cost overrun in construction projects related to client. The second sub section is include a list of factors lead to cost overrun related to contractor. The third sub section is include the cost overrun related consultant and designer factors .Finally sub section four consist the general factor lead to cost overrun in building construction project as appendix (A).

\section{Part 3: Impact of cost overrun in construction project}

This section of questionnaire survey is included six questions related the impact caused by of the cost overrun and effected building construction projects in Oman as appendix (A).

Part 4: Mitigation Measures used to control cost overrun in building projects

This section of questionnaire survey is included ten questions related to develop the best protocol strategy for project management teams that can be adopted in order to control the cost overrun as appendix (A).

\section{Data Measurement}

In this research the survey method use closed- ended questionnaire. Close issues are analyzed more easily than open one additional to that has limited alternative measures to be get reliability data and ease calculation (Sweis 2013) as show in below table (3).

Table 3: shows ordinal data measurement scale used for part 2, 3 and 4 in questionnaire.

\begin{tabular}{|l|l|l|l|l|l|}
\hline Scale & 1 & 2 & 3 & 4 & 5 \\
\hline Part (2) & Strongly Disagree & Disagree & Neutral & Agree & Strongly Agree \\
\hline Part (3) & No impact & Low impact & Medium impact & High impact & Very high impact \\
\hline Part (4) & No Recommended & Quit Recommended & Neutral & Highly \\
& & & & Recommended & Strongly \\
Recommend
\end{tabular}

Analysis of data

The special program was used to analyse the static data collected from questionnaire which is Statistical Package for the Social Sciences (SPSS) version 25.

Sample Size 
Taking in to account the size samplings that covers and targeting parties working in construction industry, including clients, consultants, contractors, quantity surveyors, in order to obtain different responses regarding the objectives of the research (Subramani 2014). With regards of sample size $n, N$ is the size of population is 300 responders and e the margined of errors $1 \%$, the equation has been used to get the sample size is

$\mathrm{n}=\mathrm{N} /(1+(\mathrm{N}(\mathrm{e}))$

Equation 1: Simple size

\section{Interviews}

The methodology was used to collect data directed from people with extensive experience in various filed in the construction industry in Oman in order to identify and obtain the factors lead to cost overrun in construction industry as well as the impact of this issue to project performance and completion, in addition provide idea and opinion that help to reduce the cost overrun in construction project. Six experts all are over 15 years of experience in the construction industry have been targeted to obtain data from different project parties (owners, contractors and consultants) Appendix B presents the interview questions created and used.

Format design and sections of Interview

The interview design consist two sections the section one consist a general information about interviewees. With regards to part two include seven questions cover project's objectives as appendix (B).

Analysis interview data

The Constant Comparative Analysis method was used to analyze the information obtain from experts. This method use coding by processing the data collected in coding, then merge the data of interviews to be in cores (M. Fram 2013). The figure (1) shows the Constant Comparative analysis method process.

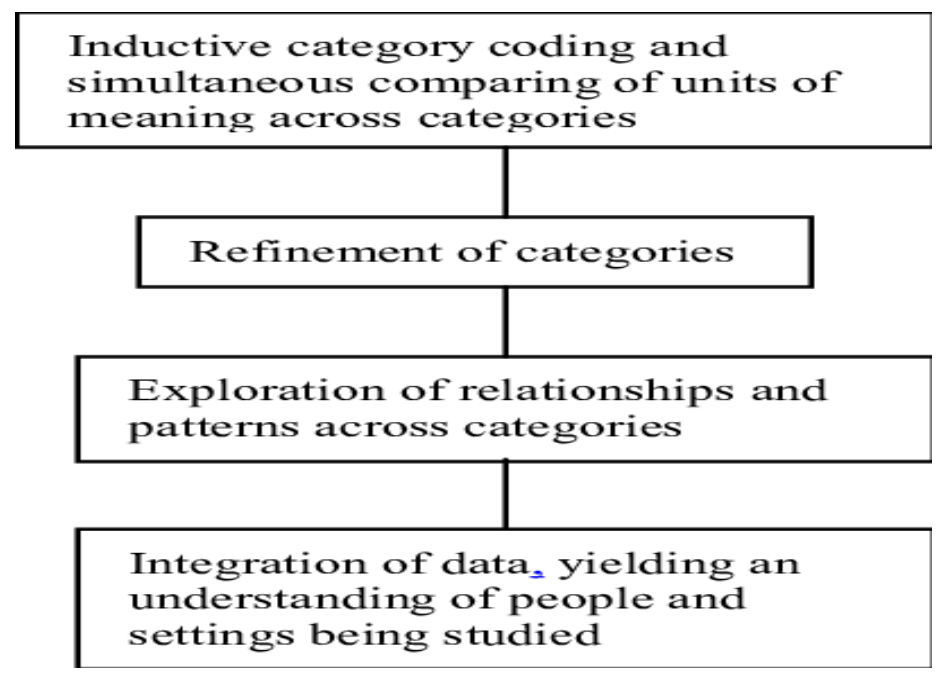

\section{Analysis and findings presentation}

In this chapter methods of questionnaire, interview have been adopted, would be presented after analyse of data obtained from participants (owners, consultants and contractors) who are working in building construction project in 
Oman. The main survey objectives are to identify and determine vital factors leading to cost overrun in Building Projects in Oman, to evaluate the impact of cost overrun in building construction projects and to develop the best protocol strategy for project management teams that can be adopted in order to control the cost overrun.

Distributing the questionnaire manually to the participants is the best way, but due the general situation and spread of New Corona Virus (COVID19) and to achieve the principle of social distance, electronic distribution was chosen as a safe alternative for all parties 298 participants were targeted to fill the questionnaire from categories (Clients, Contractor and consultants) and 252 were obtained responses from these participants.

Demographic data includes the Education Level, Organization type, Job designation, and industry type, value of recently achieved project and Percentage Extent of cost overrun. This information was contained in the questionnaire's Part 1 and is analyse appropriately and graphically mention below.

The following table shows the Cronbach's Alpha of respondent accuracy. The table (1) shows the accuracy of the respondent answers. The accuracy of responder is $91.8 \%$ which consider very good rate to obtain approved results.

Table 1: Reliability Statistics

\begin{tabular}{|l|l|l|}
\hline Item & $\begin{array}{l}\text { Cronbach's } \\
\text { Alpha }\end{array}$ & N of Items \\
\hline 1 & .918 & 44 \\
\hline
\end{tabular}

Question 1: Education Level

The figure 2 shows the type of respondent education level, that demonstrates $4.4 \%$ are diploma level, $4.8 \%$ are

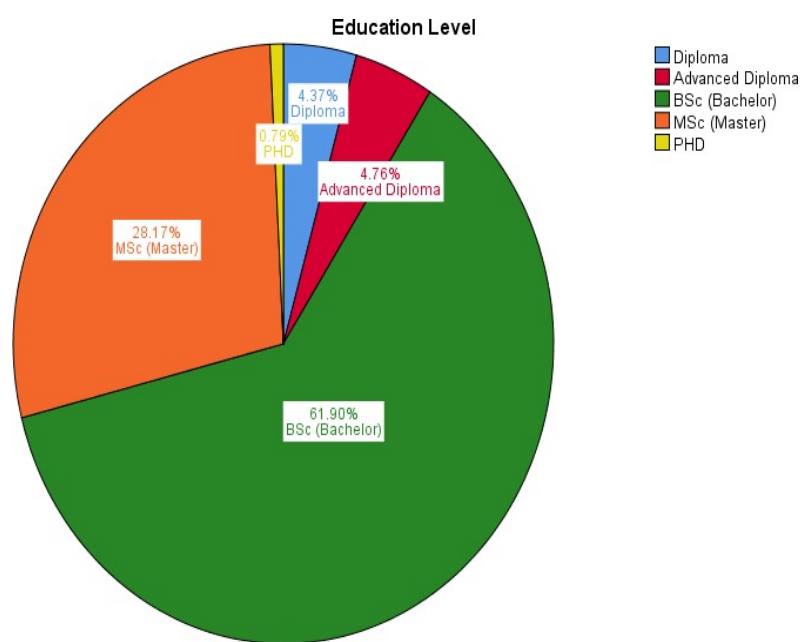

Advanced Diploma, 61.9.\% are Bachelor, 28.2\% are Master. Only 0.8 are PHD level. As shown in figure (2).

Figure 2: Educational level

Question 2: Organization type.

According to the figure 3, it shows the government sector and privet sector are almost same with 44.8 and $46.8 \%$ respectively and only $8.3 \%$ from the responders from semi government sector. AS shown in Pie Chart. 


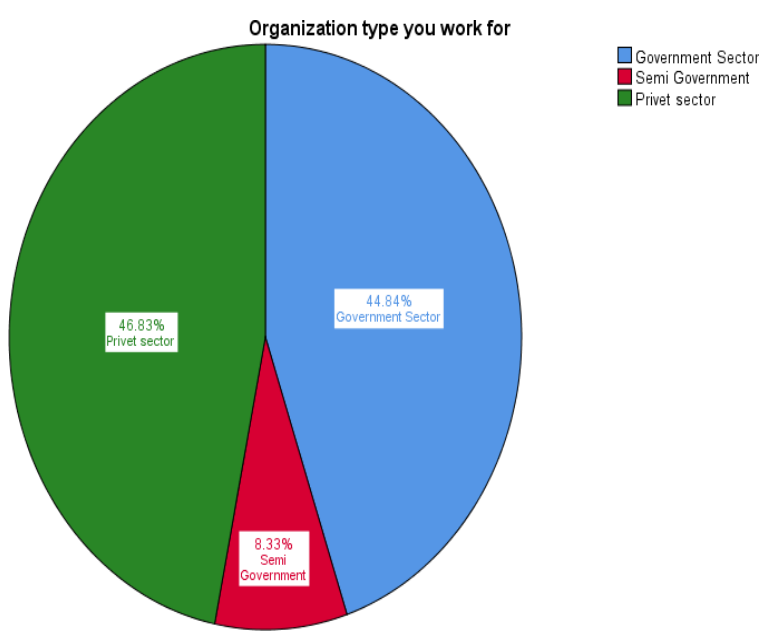

Figure 3: Organization type

Question 3: Job designation

The figure 4 shows the respondent Job designation that demonstrates that the participants from owner have 27.4 $\% .17 .1 \%$ are from Contraction Company. $19.0 \%$ of respondents are from consultancy offices $21.0 \%$ of the total participants are Quantity Surveyors. All other designations have $15.0 \%$. AS shown in Pie Chart (4).

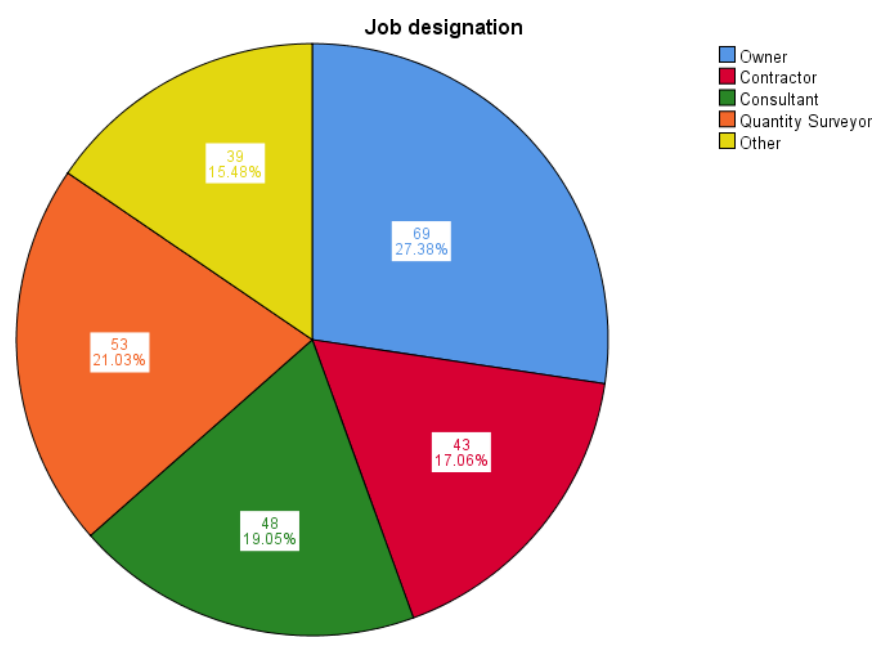

Figure 4: Job designation 
Question 4: Industry type

As shown in figure $5,44.0 \%$ of the total participants are from buildings industry sector and $46 \%$ from infrastructure industry, only 9.5 from oil and gas, $0.4 \%$ from other industry sector. That mean the questionnaire were targeting good number from building industry.

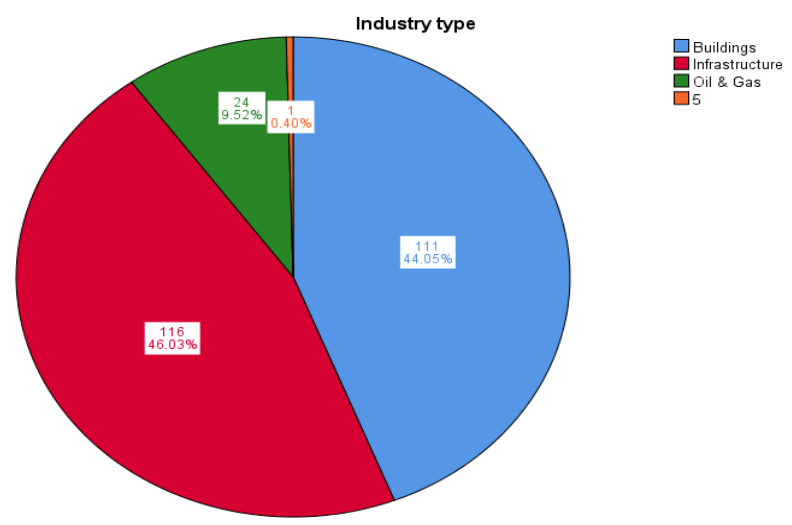

Figure 5: Industry type in construction projects

Question 5: The value of recently achieved project

Figure 6 showed that almost $53.0 \%$ of responders have been achieved the project value more than 5 million which consider majors projects as category of tender board standard. The all other project categories value are less than 20 $\%$.

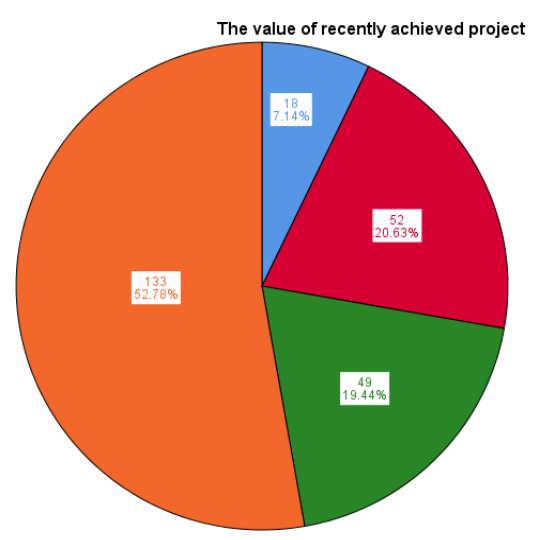

$\square O R<100,000$
$\operatorname{CoR} 100,001$ to $1,000,000$

$1,000,001<5,000,000$

ver $\mathrm{OR}, 000,000$

Figure 5: Value of recently achieved project

Question 6: Percentage Extent of cost overrun in project 
Figure 6 shows the, $0-10 \%$ the extent of cost overrun of projects have $45.6 \%$ and for $11-20 \%$ have 26.2 and with regards $21-30 \%$ have $14.7 \%$ and $31-40$ have almost $8 \%$ and finally for $41-50 \%$ value have only $5.6 \%$.

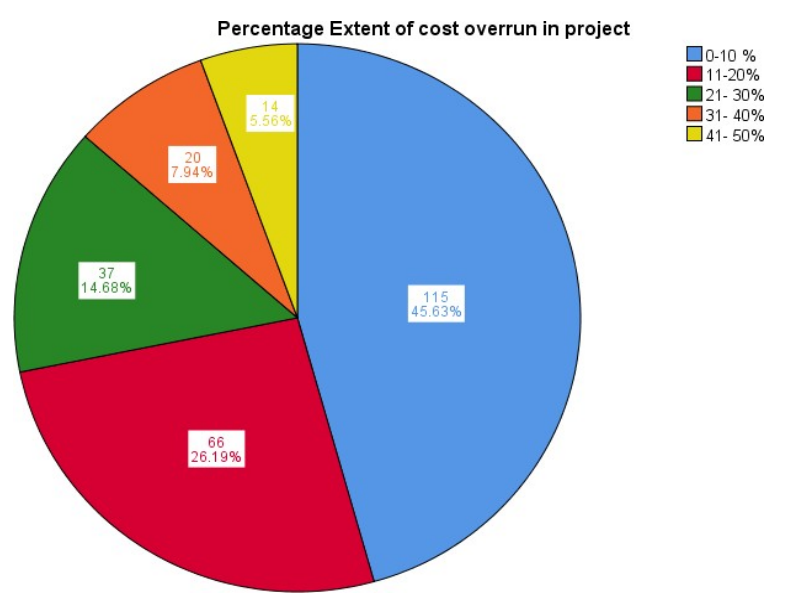

Figure 6: Percentage Extent of cost overrun in project

\section{Interpretation and Finding Data}

This consist information and data collected from the questionnaire parts 2, 3 and 4 distributed to the concern people. These answers express the questions that were asked in the survey and on this basis the researcher will conclude the research objectives after the results are properly and fully evaluated.

Part 2: Factors Leads to cost overrun in Building construction in Oman: this part is covering the objective number one which is analyzing the factors that lead to cost overrun in building construction project in Oman. The factor have been classified related to (Client, Contractor, Consultant and General)

Client related factors

F1: Delay in approval and process of payments certificate.

Approximately $38 \%$ of the total participants agreed with viewpoint of this factor is affected the cost overrun of construction project in the Sultanate of Oman, and $14.7 \%$ of them are strongly agreed with this view as well, while $31.7 \%$ are neutral to this factor. This is considered a great indication, this factor is influences the cost overrun in building construction projects. As shown in Figure 7. 


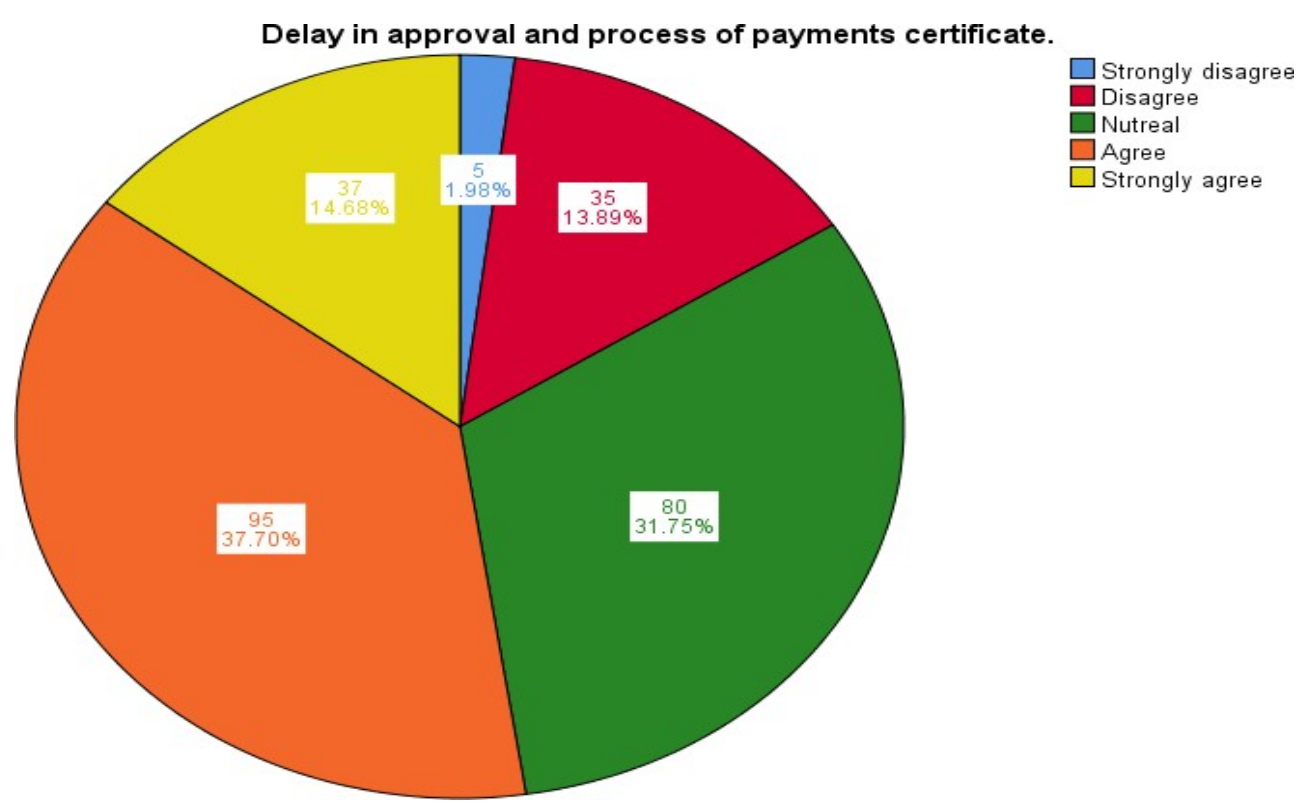

Figure 7: Approval and process of payments certificate

F2: Delay to handover the site to the contractor.

Approximately $34 \%$ of the participants, they believed agreed about this factor affecting cost overrun in building construction project in Oman, 30.2\% of the total respondents have neutral While 24.6. \% are disagree. As shown in figure 8 .

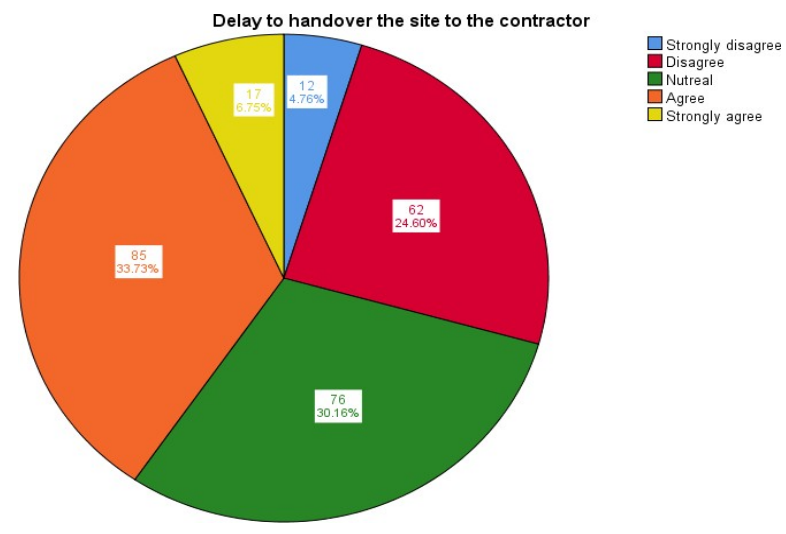

Figure 8: Delay to handover the site to the contractor F3: Regular change orders during execution the work Approximately $42 \%$ of the total participants agreed with viewpoint of this factor is affected the cost overrun of construction project in the Sultanate of Oman, and $29.8 \%$ of them are strongly agreed with this view as well, while $14.3 \%$ are neutral to this factor. Only $11.9 \%$ disagree . This is considered a great indication, this factor is effecting the cost overrun in building construction projects. A shown in figure 9. 


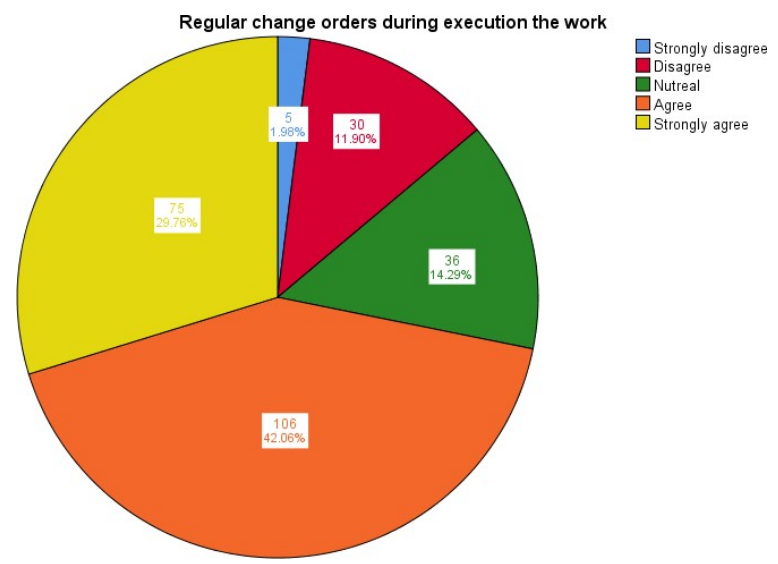

Figure 9: Regular change orders during execution the work

F4: Delay to approve design documents in construction stage

Almost two third of total participants agreed and strongly agreed that delay in approval of design documents in construction stage affected the cost overrun of construction projects in the Sultanate of Oman. While approximate one fifth felt neutral about of this factor. Only $13.9 \%$ are disagree. This is considered a great indication, this factor is effecting the cost overrun in building construction projects. AS shown in Pie Chart (11).

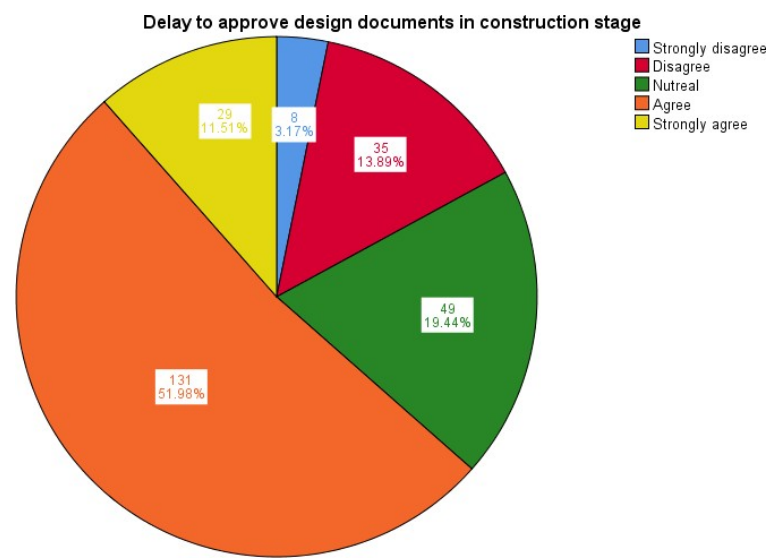

Figure 10: Delay to approve design documents in construction stage

F5: Work progress suspension by clients Table 15: Work progress suspension by clients

In figure 11, almost half of total participants agreed and strongly agreed that Responses on work progress suspension by clients affected the cost overrun of construction projects in the Sultanate of Oman. While quite more than quartier felt neutral about of this factor. And one fourth are disagree about this factor. This is considered a great indication, this factor is effecting the cost overrun 


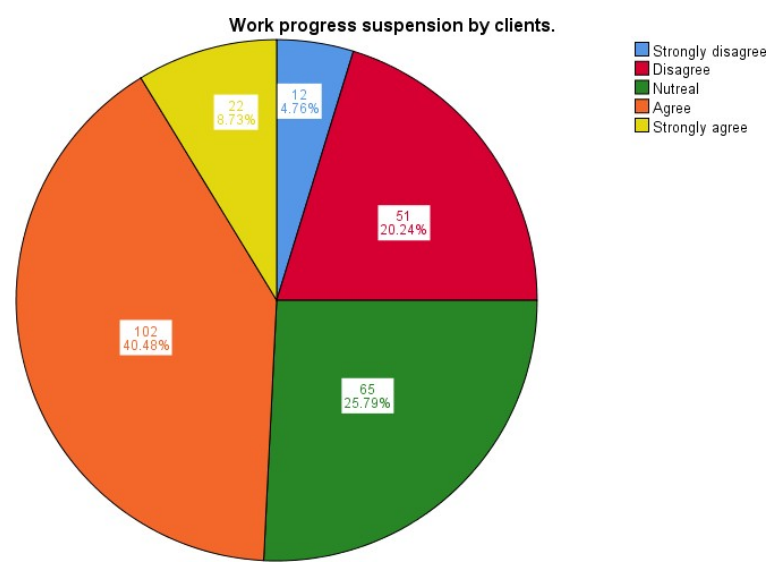

Figure 11:Work progress suspension by clients.

F6: Delay in decision making procedure Table 16: Delay in decision making procedure According to survey result, more than two third of total participants agreed and strongly agreed that delay in decision making procedure in affected the cost overrun of construction projects in the Sultanate of Oman. While approximate one fifth felt neutral about of this factor. This is considered a great indication, this factor is effecting the cost overrun in building construction.

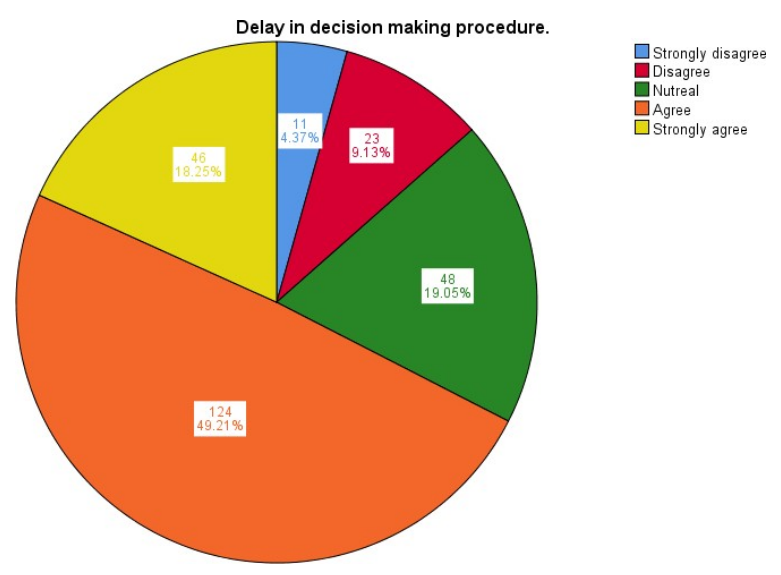

Figure 12: Delay in decision making procedure.

Contractor Related Factor

F7: Poor cost control plan use in construction project. Table 17: Poor cost control plan use in construction project. Approximately $40 \%$ of the total participant agreed with viewpoint of this factor is affected the cost overrun of construction project in the Sultanate of Oman, and $22.6 \%$ of them strongly agreed with this view as well, while 17.5 $\%$ are felt neutral to this factor.This is considered a great indication, this factor is effecting the cost overrun in building construction projects .These Data are shown in a pie chart (14). 


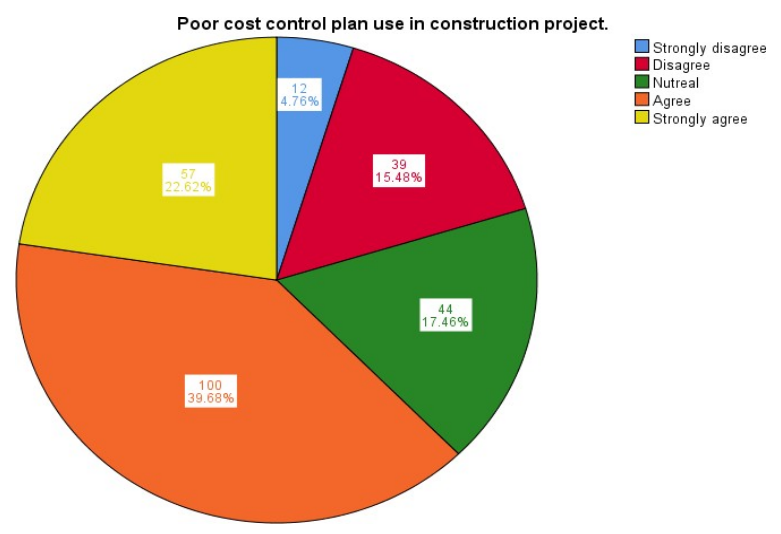

Figure 13: Lack of contractor's experience and poor coordination b/t contractor and other parties F8: Lack of contractor's experience and poor coordination $b / t$ contractor and other parties.

According to the survey result, more than two third of total participants agreed and strongly agreed lack of contractor's experience and poor coordination $\mathrm{b} / \mathrm{t}$ contractor and other parties is affected to cost overrun of construction projects in the Sultanate of Oman. This is considered a great sign, this factor is effecting the cost overrun in building construction projects . These data are presented in a figure 14 .

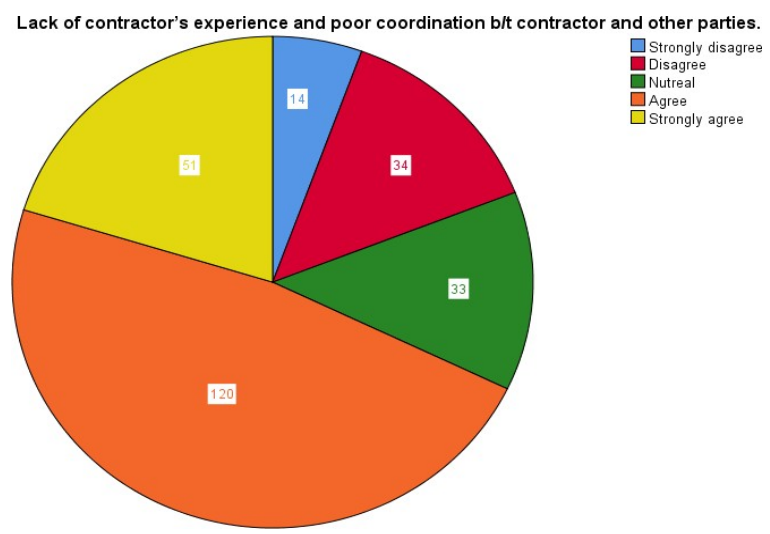

Figure 14: Lack of contractor's experience and poor coordination b/t contractor and other parties.

F9: Financial difficulties by contractors

According to survey result, more than two fifth of the total participant agreed about this factor affecting cost overrun in building construction project in Oman and $23.3 \%$ of the total participants are strongly agreed. $17.9 \%$ of them felt neutral. The lowest of them all are strongly disagreed which has a percentage of $3.6 \%$. This simple indicates that in building projects effected by this factor. These data are displayed in Pie Chart (16). 
Muscat, Oman 2021

Figure 15: Financial difficulties by contractors

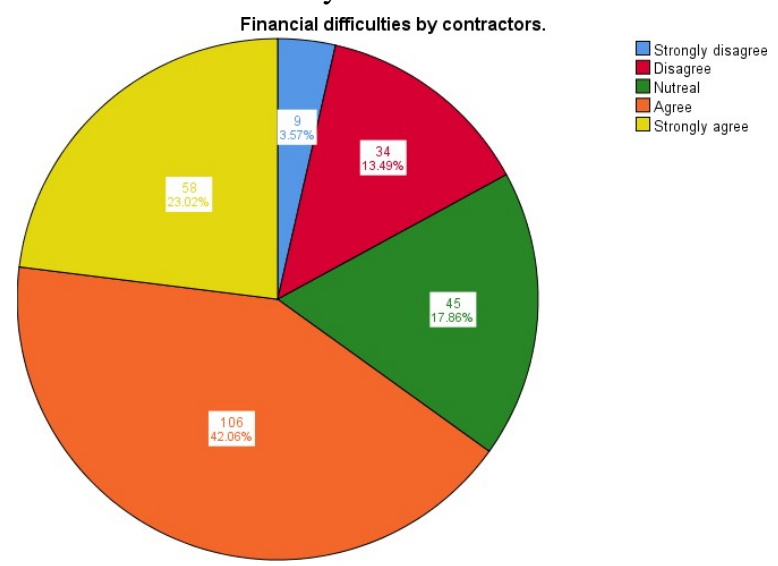

F10: Ineffective planning and scheduling of construction program Table 20: Ineffective planning and scheduling of construction program

In line with the survey result, more than two third of total participants agreed and strongly agreed, Ineffective planning and scheduling of construction program is affected to cost overrun of building construction projects in the Sultanate of Oman. While $19.0 \%$ felt neutral about of this factor. This is reflected as very high indication, this factor is effecting the cost overrun in building construction projects. These data are presented in a pie chart (17).

Pie Chart 16: Ineffective planning and scheduling of construction program

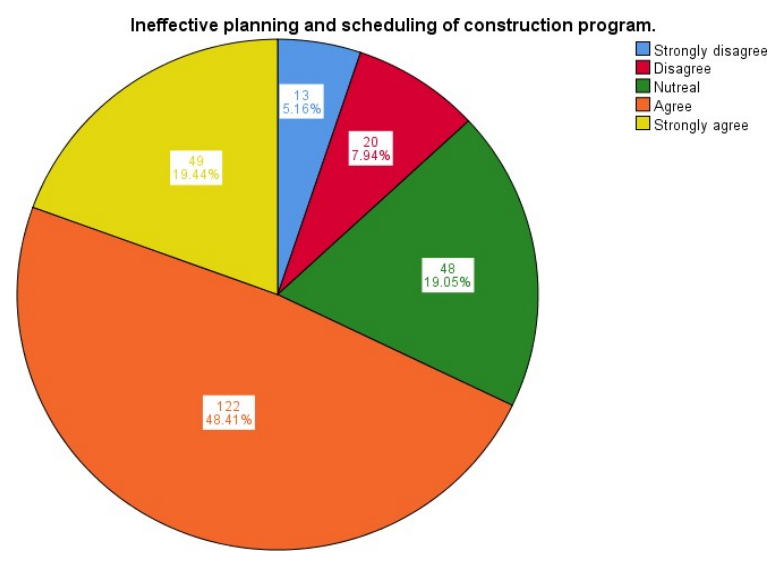


F11: Poor site management by contractors.

$41 \%$ of the total participants agreed with viewpoint of this factor is affected the cost overrun of construction project in the Sultanate of Oman, $23.4 \%$ of them strongly agreed with this view as well, while $16.7 \%$ felt neutral to this factor, approximately $14 \%$ are disagree. This is a sign, this factor is effected the cost overrun in building construction projects .These data are shown in a figure 16

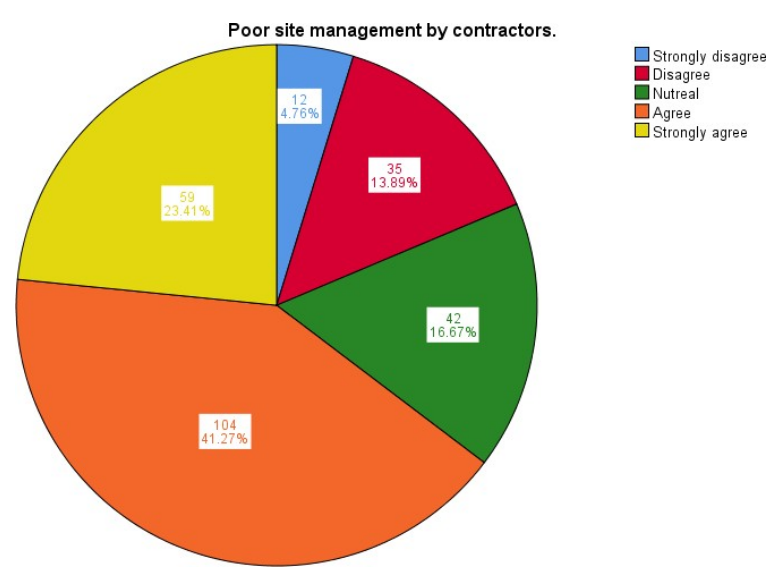

Figure 16: Poor site management by contractors

Consultant -related factors:

F12: Lack of sufficient experience of consultants.

According to the survey outcomes, $40.9 \%$ of the total participant are of the opinion that agreed about this factor affecting cost overrun in building construction project in Oman and $17.1 \%$ of the total participants are strongly agreed as well. While $19.4 \%$ are felt neutral. $17.1 \%$ of the total participant disagreed .This simple indication this factor affects the cost overrun. These data are displayed in figure (17).

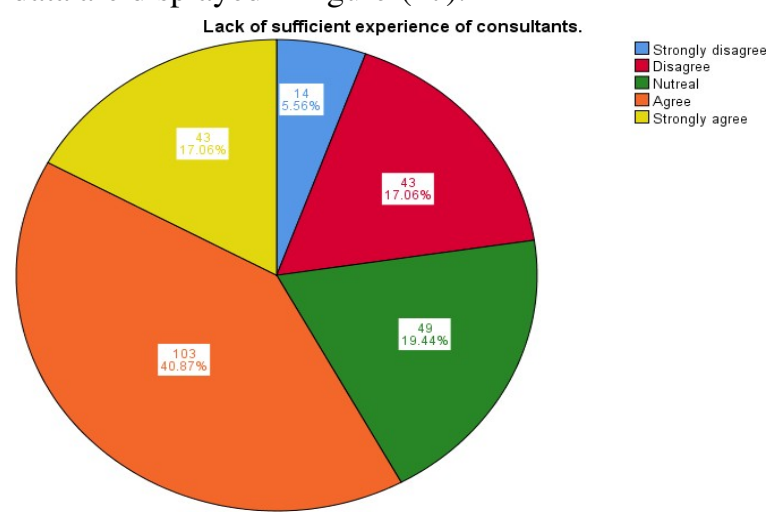

Figure 17: Lack of sufficient experience of consultants 
F13: Delay in submission of the revised design documents

According the survey result, more than two third of total participants agreed and strongly agreed delay in submission of the revised design documents is affected to cost overrun of building construction projects in the Sultanate of Oman. While $21.0 \%$ felt neutral about this factor. Only

$12.7 \%$ disagreed and strongly disagreed. This is obvious indication, this factor is effecting the cost overrun in building construction projects. These data are presented in a pie chart (20)

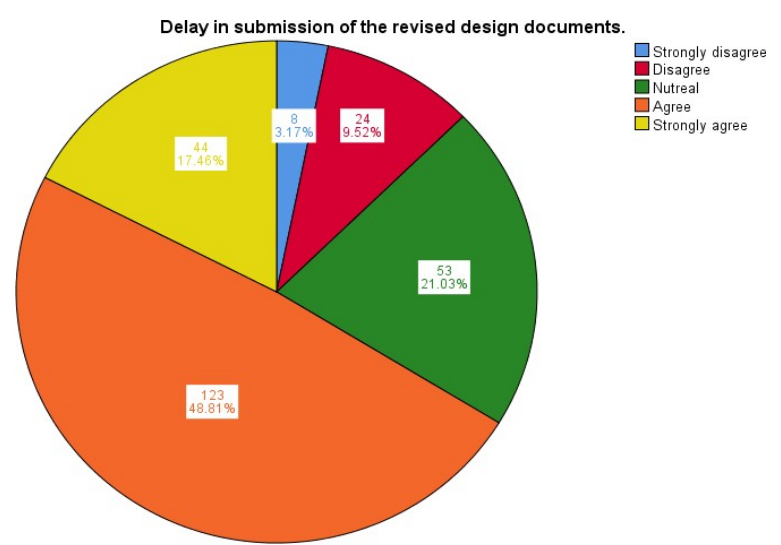

Figure 18: Delay in submission of the revised design documents

F14: Project design complexity.

According to the survey result shown in figure $19,38.5 \%$ of the total respondent's agreed about this factor Project design complexity is effected to cost overrun, while $8.3 \%$ have strongly agree.31.7 of responders felt neutral about this factor.

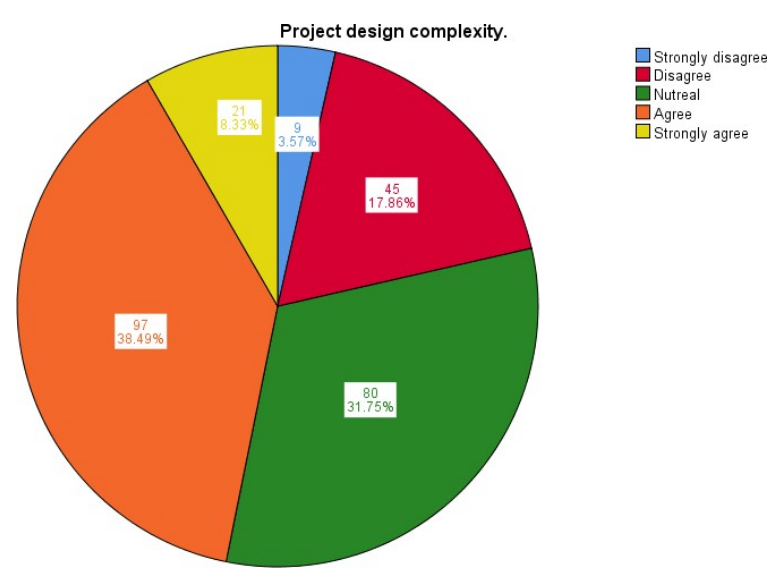

Figure 19: Project design complexity 
F15: Errors and discrepancies in design and contract documents

According to the survey result, $45.6 \%$ of the total participants agreed that this factor affects the cost overrun in building construction project in Oman. Approximate $18 \%$ of all participants are strongly agreed. While $24.2 .0 \%$ felt neutral about this factor. And only $12.3 \%$ disagree and strongly disagree. This is an evidence, this factor is effecting the cost overrun in building construction projects. These data are presented in figure 20.

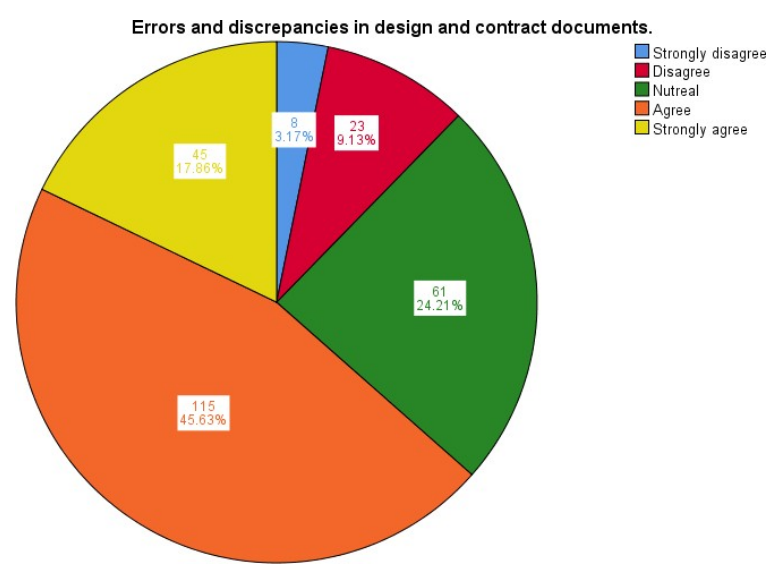

Figure 20: Errors and discrepancies in design and contract document

Part 3. Impact of cost overrun in construction project.

This part is targeting the objective number two evaluate the impact of project cost overrun in building construction project and it consist six questions.

F16: Dispute between Client and Contractor:

$27.4 \%$ of the total participants said there are high impact of cost overrun to dispute between client and contractor, while $9.9 \%$ said there is very high impact. $46.0 \%$ of total participants felt there is medium impact. About $13.9 \%$ and 2.8 said there are low impact and no impact respectively. These data are displayed in figure 21 .

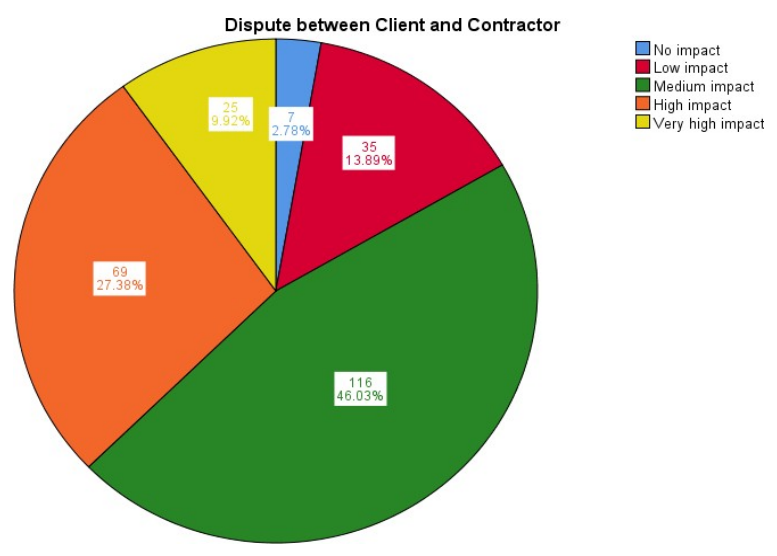

Figure 21: Dispute between Client and Contractor 
F17: Deliver poor quality

According to survey result, more than half of entire participants said there are impact of cost overrun to deliver poor quality, while 32.5 of total participate said there is medium impact.12.7

$\%$ of participants felt low and no impact. This identified that the cost overrun is effected the quality of budding construction project. These data are presented in Pie Chart (31).

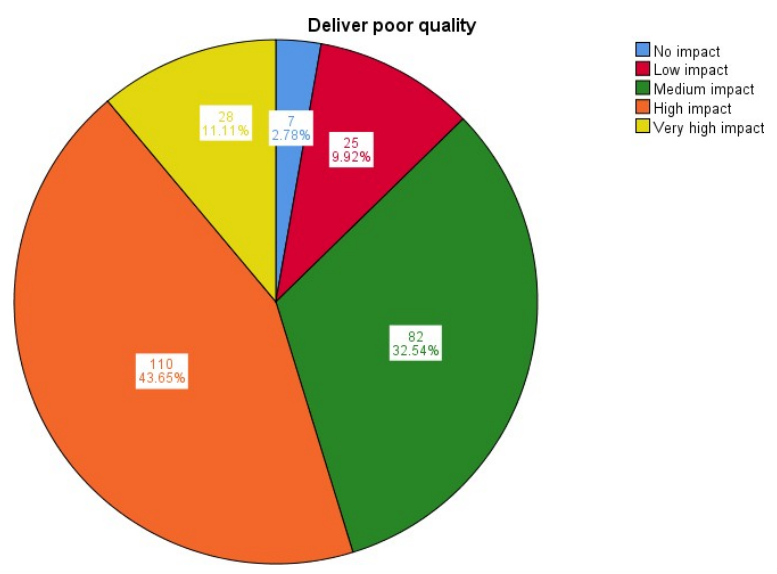

Figure 22: Deliver poor quality

F18: Delay of Payment approval.

More than half of total participants said there is impact of cost overrun to delay of contractor payment, while 32.9 of total participate said there is medium impact.13.1\% of participants felt low and no impact. This identified that the cost overrun is one of reason behind payment delay in budding construction project. These data are presented in figure

23.

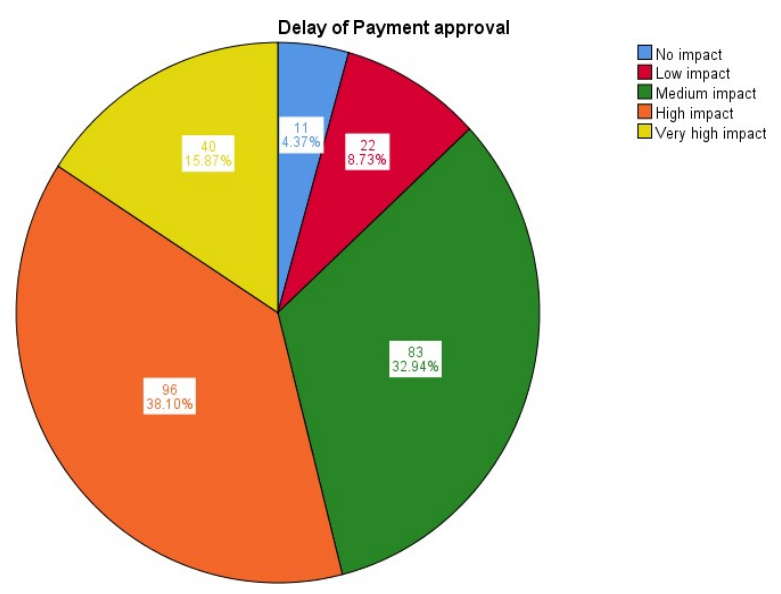

Figure 23: Delay of Payment approval

Part 4. Mitigation Measures used to control cost overrun in building projects. 
This parts is targeting the objective number 3, the steps that could mitigate the problem of cost overrun in building construction in Oman.it is consists ten questions.

F19: Award the work for experienced contractors, subcontractors and suppliers.

Based on survey data collection, $40.5 \%$ of the entire participants highly recommended that award the work for experience contractor would minims the cost overrun and $32.5 \%$ strongly recommended as well. While 21.4 felt neutral of this. $4.4 \%$ and only $1.2 \%$ quite recommend and no recommended respectively. This statistics are displayed in figure 24.

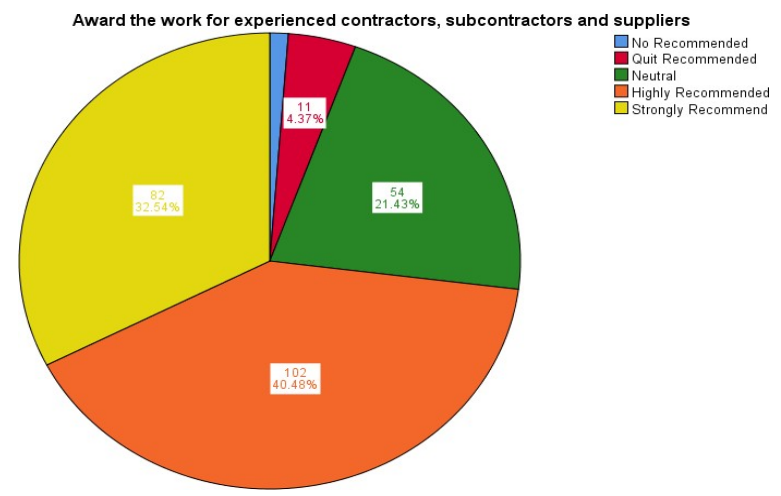

Figure 24: Award the work for experienced contractors, subcontractors and suppliers

F20: Well planning for pre-contract stage and use proper procurement strategy

According to survey data, approximate $80 \%$ of total participants recommended that well planning for pre contract stage and use proper procurement would minims the issue of cost overrun in building construction project.14.3 \% of participants felt neutral. About $4.8 \%$ and $2 . \%$ quite recommend and no recommended respectively. This is cleared, that this factor may control the cost overrun in future project. These data are presented in figure 25.

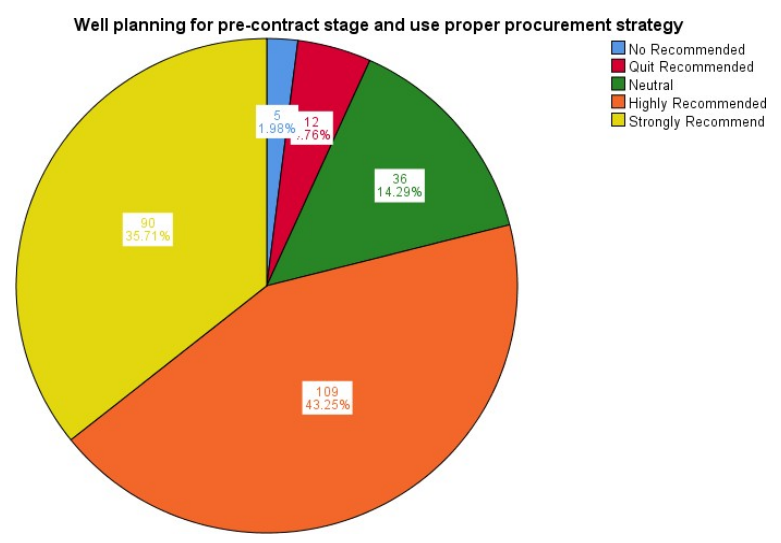

Figure 25: Well planning for pre-contract stage and use proper procurement strategy

The major factors effects the cost overrun in building construction projects in Oman.

From the questionnaire survey, it shows that the major factors effected the cost overrun in construction projects in Oman result in (research objective 1). To define the five major Factors, the mean score Rate as follows.

Table 2: Classification of the major factors lead to cost overrun in building construction project in Oman. 


\begin{tabular}{|l|l|l|l|}
\hline Rank & Group & cost overrun factors & Percentage \\
\hline 1 & Client related & $\begin{array}{l}\text { Regular change orders during execution the } \\
\text { work. }\end{array}$ & 71.90 \\
\hline 2 & Contactor related & $\begin{array}{l}\text { Lack of contractor's experience and poor coordination } \\
\text { b/t contractor and other }\end{array}$ & 67.80 \\
\hline 3 & Contactor related & Ineffective planning and scheduling of \\
& & construction program. & 67.80 \\
\hline 4 & Client-related & Delay in decision making procedure. & 67.50 \\
\hline 5 & Consultant -related & Delay in submission of the revised design & 66.30 \\
& & documents. & \\
\hline
\end{tabular}

The impact of cost overrun in construction project in Oman.

From the questionnaire survey result, it shows that the major impact of cost overrun in building construction project in Oman (research objective 2). To define the major Impacts, the mean score Rate as follows.

Table 3: Classification of the major Impact to cost overrun in building construction project in Oman.

\begin{tabular}{|l|l|l|}
\hline Rank & Impact & Percentage \\
\hline 1 & Time of completion & 63.80 \\
\hline 3 & Deliver poor quality & 54.80 \\
\hline & Delay of Payment approval & 54.00 \\
\hline
\end{tabular}

4.2.4 The best protocol practice can be follow to control the issue of cost overrun in construction project in Oman.

From the questionnaire survey result, it shows that the best protocol may assist to control and minimize the issue of cost overrun in building construction project in Oman (research objective). To define the best fife protocols, the mean score Rate as follows.

Table 4: Classification of the five best protocol to control cost overrun in building construction project in Oman.

\begin{tabular}{|l|l|l|}
\hline Rank & Best protocol & Percentage \\
\hline 1 & Hire a good Supervision Team and Project Manager. & 80.6 \\
\hline
\end{tabular}




\begin{tabular}{|l|l|l|}
\hline 2 & Hire a good project design team. & 80.5 \\
\hline 3 & $\begin{array}{l}\text { Well planning for pre-contract stage and use proper procurement } \\
\text { strategy. }\end{array}$ & 77.8 \\
\hline 4 & Hire a good Cost Controller (Quantity Surveyor). & 76.2 \\
\hline 5 & Consider the Risk assessment and Risk Control. & \\
\hline
\end{tabular}

\subsection{Interview Analysis}

Six Interviews were conducted with experts in various field in construction industry (Owner, Contractor and consultant) they have been chosen according as their knowledge and experience in construction industry, all of them has more than fifteen years of experience.

The questions were divided into two parts, the part one include general information about the interviewees and part two, which include seven questions cover all three objectives of research appendix (B). The experts answers are summarizes as follows:

What are the major causes that you believe are leading to cost overrun in building construction in Oman?

Table 5: Factors identify by Experts can lead to cost overrun:

\begin{tabular}{|l|l|}
\hline No & factors can lead to cost overrun \\
\hline 1 & Frequent changes in scope. \\
\hline 2 & Delay in decision making \& improper planning. \\
\hline 3 & Delays in getting approvals from various agencies. \\
\hline 4 & Improper planning \& Monitoring in project execution by contractor. \\
\hline 5 & Lack of proper reviews of the document by client and consultant. \\
\hline 7 & Client/consultant demanding unrealistic time for project completion in tender, \\
\hline 8 & Delay Payment certificate from the client. \\
\hline
\end{tabular}

What procedures do you follow to limit cost overrun in building construction projects in Oman?

Table 6: Procedures can limit cost overrun in building construction projects

\begin{tabular}{|l|l|}
\hline No & Procedures can limit cost overrun in building construction projects \\
\hline 1 & Timely payment and variation approval procedure. \\
\hline 2 & Implementing change management procedure \\
\hline 3 & Decision making procedure \& proper planning technique. \\
\hline
\end{tabular}




\begin{tabular}{|l|l|}
\hline 4 & Set up cost management with the cost control system. \\
\hline 5 & Detailed and final Design including proposed materials and finishing. \\
\hline
\end{tabular}


6 Ensure that competent staff are available with the contractor and consultant.

What obstacles do you face to implement these procedures in real building construction project?

Table 7: Obstacles face to implement the procedures in real building:

\begin{tabular}{|l|l|}
\hline No & Obstacles face to implement the procedures in real building \\
\hline 1 & Cash flow problems \& Financial support from bank. \\
\hline 3 & Inadequate risk management, poor planning and Lack of communication. \\
\hline 4 & Dequirement changes from Public agencies and client during construction stage. \\
\hline
\end{tabular}

How much the percentage of cost overrun in construction projects in Oman, from the projects you encountered The average of percentage of all responders are 33.3 per cent.

What are the impacts of cost overrun in project construction in Oman that hinders success?

Table 8: impacts of cost overrun in project construction in Oman:

\begin{tabular}{|l|l|}
\hline No & Impacts of cost overrun in project construction in Oman \\
\hline 1 & $\begin{array}{l}\text { Negative Impacts on the Economy and increase in capex, delay in earning revenue. } \\
\text { And deliver poor quality. }\end{array}$ \\
\hline 2 & Increase in legal cases and claims and litigation to project failure. \\
\hline 3 & Time impact - delayed completion. \\
\hline
\end{tabular}

Would you like to suggest other appropriate project management protocols that can minimize the cost overrun in future projects?

The interviewees believed that there are protocols can minimize and avoid the cost overruns in construction project as mentioned at table (56):

Table 9: protocols can minimize and avoid the cost overruns in construction Project:

\begin{tabular}{|l|l}
\hline No & protocols can minimize and avoid the cost overruns in construction Project
\end{tabular} 


\begin{tabular}{|l|l|}
\hline 1 & $\begin{array}{l}\text { Proper planning through review of the management Plan pre \& post contract } \\
\text { award, Keep Stakeholders updated and regular monitoring. }\end{array}$ \\
\hline 2 & Quick decision making. \\
\hline 3 & Standardize the design wherever possible. \\
\hline 5 & Promote the use of Precast Construction Technology. \\
\hline 6 & $\begin{array}{l}\text { Single window clearance for getting approvals from various agencies and Setup an } \\
\text { agency which deals with centralized GIS data of all the utilities. }\end{array}$ \\
\hline
\end{tabular}

Any more information do you want to share or suggest to minimize the negative impacts of cost overrun in future projects?

Table 10: The suggestions of experts to decrease the negative impact of cost overrun in building construction

\begin{tabular}{|l|l|}
\hline No & suggestions of experts to decrease the negative impact of cost overrun in building construction \\
\hline 1 & Collecting information about other organizations experiences in financial and Technical aspects. \\
\hline 3 & Realistic project estimate should be made and award the work only to the most competent contractor \\
\hline 4 & Hire a good consultant either for design or execution phase. \\
\hline 6 & Proper planning, Clear Communication and responsibility from Initial stage. \\
\hline
\end{tabular}

\section{Conclusion}

Based on the general results of the research and surveys that were carried out to obtain the objectives of research, it conclude the five main factors behind the cost overrun in building construction project as flowing :

Regular change orders during execution the work.

Lack of contractor's experience and poor coordination b/t contractor and other parties.

Ineffective planning and scheduling of construction program.

Delay in decision making procedure.

Delay in submission of the revised design documents.

In addition to that, the three most impacts of cost overrun in building construction sectors are:

Time of completion.

Deliver poor quality.

Delay of Payment approval. 
With regard to best five protocols to control cost overrun in building construction project in Oman. The best five protocols concluded from survey are:

Hire a good Supervision Team and Project Manager.

Hire a good project design team.

Well planning for pre-contract stage and use proper procurement strategy.

Hire a good Cost Controller (Quantity Surveyor).

Consider the Risk assessment and Risk Control.

\section{Limitations}

In the year 2020, Covid-19 pandemic has imposed several restrictions that affected the research in many ways and at all stages. Starting from literature research stage, access to public libraries is restricted. Moreover, the research study type was questionnaire and interviews based, which is hindered by the inability to physically meet participants. This has led to several questionnaires being not filled and hence excluded from the study, as well as the possibility of participants not understanding the questions is there.

\section{Acknowledgements}

I am eternally grateful for the wisdom, comprehension and strength of Allah Almighty. He gave me this thesis to write; in His mercies.

I would like to thank the following people, without whom I would not have been able to complete this research, and without whom I would not have made it through my master's degree! I would like to thank the Department of Civil Engineering at Middle East College, especially to my supervisor Dr Omar Obidi, as well as to Dr. Hussin Yahia who guided, advised me and gave me full assistance and guidance, insight and knowledge into the subject matter steered me through this research.

I would also like to extend my deepest thanks and high appreciation to all those who helped me to complete the dissertation by helping me with the required information needed and filling out the questionnaire as well as answering the questions in the interviews.

Finally, I extend my heartfelt thanks and extreme appreciation to my dad's soul, mum and wife in specific, who were my first inspiration to finish my studies and all the family members for all the prayers, endless love and support.

\section{References}

Abusafiya, H. and Suliman, S. (2017) "Causes And Effects Of Cost Overrun On Construction Project In Bahrain: Part I (Ranking Of Cost Overrun Factors AndRisk Mapping)". Modern Applied Science 11 (7), 20

Aljohani, A. (2017) "Construction Projects Cost Overrun: What Does The Literature Tell Us?". International Journal Of Innovation, Management And Technology 137- 143

Allahaim, F. and Liu, L. (2015) "Causes Of Cost Overruns On Infrastructure Projects In Saudi Arabia". International Journal Of Collaborative Enterprise $5(1 / 2), 32$

Jangale, S., Jain, A., Pathan, A. and Kandekar, P. (2017) "Introduction To Cost Overrun In Residential Building: Its Causes And Solutions". International Journal Of Engineering Research \& Technology 6 (3), 60-62

M. Fram, S. (2013) The Constant Comparative Analysis Method Outside Of Grounded Theory. Iowa USA Moossen, H. (2019) "Construction Industry Contributes 9 Per Cent To Oman'S GDP". Oman Daily Observer. Ramabhadran, M. (2018) "An Investigation Into Cost Overrun In Construction Projects In United Arab Emirates". International Journal Of Construction Engineering And Management 7 (1), 1-21 
Raykar, P. and A.N., G. (2016) "Analyzing The Critical Factors Influencing The Time Overrun And Cost Overrun In Construction Project". International Journal Of Engineering Research 5 (1), 21-25

S. Mulla, S. and P. Waghmare, A. (2015) "A Study Of Factors Caused For Time \& Cost Overruns In Construction Project \& Their Remedial Measures". Int. Journal Of Engineering Research And Applications 5 (1), 48-53

Shah, R. (2016) "An Exploration Of Causes For Delay And Cost Overruns In Construction Projects: Case Study Of Australia, Malaysia \& Ghana". Journal Of Advanced College Of Engineering And Management 2, 41

Subramani, T. (2014) "Causes Of Cost Overrun In Construction". IOSR Journal Of Engineering 4 (6), 01-07

Sweis, G. (2013) "Factors Affecting Time Overruns In Public Construction Projects: The Case Of Jordan". International Journal Of Business And Management 8 (23)

Ullah, K., Abdullah, A. and Nagapan, S. (2016) "A Framework For Avoiding Cost Overruns In Malaysian Construction Projects". International Journal Of Advanced And Applied Sciences 3 (3) 